\title{
A integração de conhecimentos e a dicotomia compreender/explicar
}

\section{The integration of knowledge and the dichotomy understanding/explaining}

\author{
Ademar HEEMANN*
}

\section{RESUMO}

\begin{abstract}
A integração de conhecimentos é um dos princípios que constituem o pano de fundo do Curso de Doutorado em Meio Ambiente e Desenvolvimento. Nesse contexto, tem se insistido no exame das dicotomias natureza/sociedade, homem/animal, ciências/humanidades. A presente reflexão trata de alguns conceitos utilizados na abordagem dessas dicotomias, realizando incursões pelos conceitos de redução, holismo e incomensurabilidade. Concluindo, apresenta uma perspectiva para as démarches interdisciplinares construída a partir da antinomia compreender/explicar.
\end{abstract}

Palavras-chave: compreender, explicar, interdisciplinaridade

\begin{abstract}
The integration of knowledge is one of the underlying principles of the Doctoral Program in studies of Environmental and Development. Within this context, the examination of the dichotomies nature/ society, man/animal, sciences/humanities has been considerered crucial. The present reflections revolve around some of the concepts used in the discussion of these dichotomies, resorting to concepts such as reduction, holism and incommensurability. In conclusion, it offers a perspective on the routes to be taken by interdisciplinary work that starts from the antinomy understanding/explaining.
\end{abstract}

Key-words: understanding, explaning, interdisciplinary

\footnotetext{
* Professor Sênior do Curso de Doutorado em Meio Ambiente e Desenvolvimento da UFPR. E-mail: heemann@ uol.com.br. Parte desta reflexão foi publicada em HEEMANN, A. La epistemología de la convergencia y la innovación en la pedagogía a partir de la biología educativa. Ludus Vitalis, México, D.F., v. 4, n. 7, p. 75-87, 1996; e HEEMANN, A. Natureza e ética: dilemas e perspectivas educacionais. 2. ed. Curitiba: Ed. UFPR, 1998. p. 110-115; 170-174.
} 


\section{A complementaridade disciplinar}

Não há fronteira entre o vital e o mental,
entre o biológico e o psicológico.

Piaget

Sob a perspectiva da complementaridade disciplinar, as teorias e/ou disciplinas não se sobrepõem nem são concorrentes. Elas dividem a realidade em seus diversos níveis de organização e seus objetos são complementares, garantindo, dessa forma, a unidade científica. Nesse âmbito, o conceito de antidisciplina tem sido útil para compreender as aproximações, convívios, disputas e fusões que originam novas disciplinas. ${ }^{1}$

A palavra antidisciplina expressa um tipo de relação de antagonismo existente em áreas adjacentes de organização que começam a interagir. Um exemplo dessa interação é o da física com a química, gerando a físicoquímica. Assim também se entende o surgimento de outras disciplinas, como biofísica, bioquímica, biopsicologia e sociobiologia.
Sob esse entendimento, a disciplina encontra sua antidisciplina no nível inferior imediato na escala de complexidade. A física é a antidisciplina da química, que, por sua vez, é antidisciplina da biologia e assim sucessivamente. Esse esquema explicativo nasce da compreensão de que as inovações, as descobertas da antidisciplina é que irão constituir a matéria-prima para a evolução da disciplina. Vejam-se, por exemplo, os grandes avanços da biologia no campo do genoma. $\mathrm{O}$ mérito se deve à química pelas suas descobertas a respeito do DNA. Foram os avanços da antidisciplina que reformularam a disciplina que veio logo acima. Como já foi dito, a interação tensa e criativa entre esses dois campos complementares redundou em avanço para a biologia.

Essa argumentação a respeito da complementaridade científica também tem sido reforçada por uma compreensão integrativa a respeito da dicotomia reducionismo holismo. ${ }^{2}$ Sob esse olhar, conforme mostra a figura que segue, as explicações científicas obedecem a uma hierarquia.

FIGURA 1 - A REDUÇÃO E A EMERGÊNCIA DA COMPLEXIDADE



1 O conceito de antidisciplina aqui exposto foi retirado de WILSON, E. O. A natureza humana. São Paulo: T. A. Queiroz, 1981. p. 7-9.

2 BONNER, T. J. A evolução da cultura nos animais. Rio de Janeiro: Zahar, 1983. p. 14. 
Nessa hierarquia, as leis do nível inferior são necessárias, mas não suficientes para o nível imediatamente superior, ou seja, o nível incluso é necessário, porém não é suficiente para o entendimento do mais inclusivo. Essa exigência funciona nos dois sentidos. Assim, o conhecimento celular é necessário, todavia não é suficiente para o entendimento do ser vivo, cujo conhecimento é necessário, mas não suficiente para o entendimento das células que nele existem. Isso seria "verdadeiro tanto para cima como para baixo, do átomo à vida como um todo, e vice-versa". ${ }^{3}$

Graças a esse método reducionista, articulado entre os níveis hierárquicos, teriam sido possíveis os avanços da biologia, a exemplo de Darwin, que não esperou Mendel, que, por sua vez, não esperou a biologia molecular para a testagem empírica de suas hipóteses. A teoria da seleção natural não existiria sem o reducionismo, que se amparou em um antecedente, dito de outro modo, em uma perspectiva holista. ${ }^{4}$

Essa visão de complementaridade disciplinar tem se mostrado fecunda nos limites do paradigma das ciências naturais. As perplexidades se avolumam, no entanto, quando se pretende transpor o espaço que as separa das ciências humanas. Dificuldades epistemológicas, entremeadas com as mais diversas críticas ideológicas, tornam esse projeto utópico ou, pelo menos, ousado, porquanto tem sido muito difícil um diálogo nesse terreno. ${ }^{5}$ A crença na complementaridade de objetos e na semelhança dos procedimentos metodológicos fica abalada quando se atenta para as motivações ideológicas, a variabilidade dos recortes e as formas de reconstrução da realidade.

Sugere-se, então, que o instrumental explicativo até aqui utilizado não foi suficiente para consolidar a démarche que superaria a descontinuidade entre as ciências naturais e as ciências humanas. Em regra, ao invés da complementaridade, os autores enfatizam a incompatibilidade. Diferentes estudiosos, analisando os mesmos dados, tiram con- clusões diferentes e, ao se combaterem, comumente nem chegam a se comunicar, uma vez que se encontram separados por grandes distâncias em termos de objeto, método e ideologia. Os contendores, ao brandirem suas verdades, seguramente estariam realizando um diálogo de surdos.

Essa incomunicabilidade pode ser exemplificada pelo celeuma causado pelo tema da inteligência. Os culturalistas, embora não neguem de público a base hereditária, privilegiam a opção social, resistindo à versão hereditária, no temor de que tal modelo possa alimentar a desigualdade sociopolítica. ${ }^{6}$ Evidente que a ideologia está presente, pois, como diz o renomado biólogo Frota-Pessoa, não há dados científicos que neutralizem as preferências doutrinárias dos cientistas. $^{7}$ Mas, segundo a vanguarda biológica, a crítica ideológica não invalidaria a possibilidade de uma crítica epistemológica do elemento objetivo contido no discurso do cientista. Nessa altura, no entanto, o diálogo em geral já foi interrompido.

Admitindo-se, com Saussure, que o ponto de vista cria o objeto e que é inegável a incomensurabilidade conceitual e metodológica entre as ciências naturais e as humanidades, isso não implica, necessariamente, que se deva renunciar à busca de uma integração de conhecimentos. Daí porque a própria maneira de abordar esses obstáculos epistemológicos e ideológicos já encerra, em si, uma pedagogia. Há muito mais coisa envolvida, mas de começo é possivel acreditar que no estudo da natureza e da sociedade o homem não precisa fazer de conta que paira sobre elas. Como parte da natureza e dependendo da cultura circundante, é possível ao homem adotar uma postura que intencionalmente se afaste da persuasão e que se aproxime da abertura e disponibilidade para uma démarche compreensiva.

Na vivência prática e na espontaneidade do ato criativo, ${ }^{8}$ esse obstáculo da incomensurabilidade já estaria superado graças ao fenômeno da compreensão. Esse é o mo-

3 SIMPSON, G. G. A biologia e o homem. São Paulo: Cultrix, 1974. p. 16 e 22.

4 Reducionismo é aqui entendido não como filosofia da diminuição, mas como a essência do método científico. A palavra holismo (hólos) quer dizer totalidade. "Referese a uma compreensão da realidade em função da totalidade integrada cujas propriedades não podem ser totalmente reduzidas a unidades menores". Cf. SIMPSON, op. cit. p. 20 e 22.; KAPRA, F. O ponto de mutação. São Paulo: Cultrix, 1982. p. 13.

5 O termo paradigma pode significar um suposto acordo, em grande medida irrefletido, entre os pesquisadores bem como o "pensamento e a prática dele decorrentes". Diz respeito aos problemas, ao tipo de respostas e aos métodos admitidos pela "comunidade científica". Cf. CUPANI, A. A crítica do positivismo e o futuro da filosofia. Florianópolis: Editora da UFSC, 1985. p. 57-58; KUHN, T. S. A estrutura das revoluções científicas. São Paulo: Perspectiva, 1982. p. 57-66.

6 ADES, C. Psicologia diferencial. Dante Moreira Leite. Folha de São Paulo, 20 abr. 1986. Ilustrada, p. 86.

7 Cf. FROTA-PESSOA, O. Sociobiologia - o fator genético. Folha de São Paulo, 2 mar. 1986. p. 27. Veja-se em Althusser o elemento imaginário e idealista no discurso do cientista, denominado filosofia espontânea do sábio; Cf. ALTHUSSER, L. Filosofia e filosofia espontânea dos cientistas. Lisboa: Presença, 1976.

8 Veja-se em GUSDORF, G. A interdisciplinaridade. Ciências Humanas, v. 1, n. 2, p. 16, 1977, a argumentação de que a inteligência humana já é, por essência, interdisciplinar. 
mento, portanto, para uma breve aproximação com o contexto da hermenêutica, que poderá trazer benefícios aos intentos do diálogo interdisciplinar e de uma abordagem integradora do conhecimento.

\section{A estrutura circular da compreensão}

A dualidade compreender/explicar tem sido utilizada para explanações a respeito dos limites entre as ciências humanas e as naturais. Esses limites têm suas origens na antiga controvérsia que marca a cultura ocidental sob a denominação cultura versus natureza. Grosso modo, para as humanidades a palavra-chave seria a compreensão e para as ciências, a explicação. Uma breve consideração sobre esses termos auxiliará no avanço da reflexão.

$\mathrm{O}$ conceito de compreensão liga-se historicamente à clássica dualidade entre razão (sede do pensamento racional mais elaborado) e intelecto (ao qual dizem respeito a empatia, a intuição, a emoção, o sentimento e o subjetivo). Essa dualidade remete ao par de conceitos explicar (Erklären) e compreender(Verstehen). Nas ciências, busca-se, mediante o reducionismo metodológico, o nexo causa-efeito, isto é, a explicação. Compreender, no entanto, implica a apreensão de um sentido, transcendendo, pois, à explicação causal. ${ }^{9}$

A explicação, como já foi indicado, pressupõe uma compreensão prévia. Assim, descrever ou interpretar um fenômeno implica já tê-lo compreendido, pois, conforme Heidegger, "interpreta-se o mundo já compreendido". ${ }^{10}$ Mas essa compreensão depende de um evento ainda mais original: a pré-compreensão. ${ }^{11}$ É o primeiro acesso ao horizonte de pressupostos que originam uma nova compreensão, resultando daí uma reciprocidade. Nos termos de Gadamer, "assim se movimenta a dinâmica da compreensão, do todo para a parte e de volta para o todo". ${ }^{12}$ Essa reciprocidade, chamada de "estrutura circular da compreensão", também poderá ser visualizada na forma de uma espiral ascendente.
Esse horizonte de pressupostos e compreensões prévias (ideologia, intuição, sonhos), presente no contexto da descoberta, é omitido no contexto do relato científico, que procura enfatizar ${ }^{13}$ a objetividade na relação sujeito/objeto. Esse fato dificulta a identificação das estruturas de mediação no plano teórico, pois, como observou Gusdorf, "o homem que persegue o conhecimento não se dá conta de que é ao mesmo tempo sujeito e objeto da pesquisa". ${ }^{14}$

Paradoxalmente, tal fato parece não impedir as possibilidades de trânsito entre o domínio das ciências naturais e o das humanidades no contexto da descoberta. Em outras palavras, a descoberta transcenderia aos limites impostos pela disciplinaridade. Quantos cientistas já não revelaram que acreditam terem chegado às suas teorias a partir de "sonhos ou estados semelhantes ao do sonho; por força de um lampejo de inspiração; e até mesmo em virtude de malentendidos, de enganos". ${ }^{15}$

Pelo que foi visto, a dualidade compreenderlexplicar como critério de limitação entre o campo das ciências e o campo das humanidades também fica sob suspeita. Seria uma falsa dicotomia?

Comentou-se, anteriormente, que se avolumam os questionamentos referidos de um modo geral à necessidade de integrar conhecimentos, em especial nos empreendimentos de natureza interdisciplinar, como o curso de Doutorado em Meio Ambiente e Desenvolvimento.

A complexidade contida nesses questionamentos transcende, em grande parte, ao âmbito da explicação, dizendose, por isso, que eles seriam apreensíveis através do processo da compreensão. Surge, no entanto, o obstáculo representado pela incomensurabilidade entre teorias e diferentes motivações ideológicas, criando o que Morin ${ }^{16}$ denominou de "fosso" entre as ciências naturais e as humanas.

Argumentou-se, então, que, se por um lado a incomensurabilidade constitui um óbice para o livre trânsito entre algumas áreas disciplinares, por outro , a idéia da estrutura circular da compreensão pode contribuir com o processo que procura transpor essas rígidas barreiras, reais ou construídas por um equívoco metodológico.

9 CORETH, E. Questões fundamentais de hermenêutica. São Paulo: E.P.U., 1973. p. 45-48.

10 Do original "Die schon verstandene Welt wird ausgelegt". Cf. HEIDEGGER, M. Sein und Zeit. Tuebingen: Max Niemeyer, 1977. p. 148 e 150.

11 LADRIERE, J. Filosofia e práxis científica. Rio de Janeiro: Francisco Alves, 1978. p. 23.

12 GADAMER, H.-G. Wahrheit und methode. Tuebingen: J. C. B. Mohr, 1965. p. 275.

13 Sobre o papel da intuição como fator preponderante nas descobertas e invenções da Física, cf. BASSALO, J. M. F. O papel da intuição nas descobertas e invenções em física. Ciência e Cultura, São Paulo, v. 38, n. 11, p. 1835-1848, 1986.

14 GUSDORF, op. cit., p. 16.

15 Relato de POPPER, apud MAGEE, E. B. As idéias de Popper. São Paulo: Cultrix, 1974. p. 38.

16 MORIN, E. O enigma do homem. São Paulo: Círculo do Livro, 1973. p. 55-59. 
Vale introduzir, aqui, as palavras de Gusdorf quando diz que é "a partir de sua própria realidade que o homem pode pensar tudo o que pensa". ${ }^{17}$ Assim, as vivências do autor dessa reflexão reforçaram, cada vez mais, a idéia da convergência. $\mathrm{O}$ que no início era apenas uma percepção intuitiva adquiria, com o tempo, os contornos passíveis de uma sistematização. A princípio, era a suspeita de que a oposição entre compreender/explicar poderia ser uma falsa antinomia, uma barreira artificial. Os produtos do trabalho em equipe com especialistas de diferentes áreas apontavam para uma direção integrada, embora ainda um tanto nebulosa, sem uma exata consciência teórica dos acontecimentos que produziam aqueles resultados.

Nesse clima de incertezas, foram úteis as palavras de Gadamer, enunciando que a dinâmica da compreensão se movimenta "do todo para a parte e de volta para o todo". Quer dizer: a oposição compreender/explicar só poderia ser presumida quando se acreditasse que, por um lado, a explicação, obtida pela redução do fenômeno à(s) sua(s) causa(s), fosse o componente único do método científico e, por outro, a compreensão fosse uma ferramenta exclusiva das humanidades. ${ }^{18}$

Ora, de acordo com as exposições anteriores (círculo hermenêutico e holismo/reducionismo), quem explica já compreendeu, ou seja, só resolvemos problemas que já foram compreendidos. Nesse clima de questionamento, recorre-se às idéias de Popper, ${ }^{19}$ resumidas no enunciado que segue:

Assim como compreendemos outras pessoas devido à humanidade de que participamos, podemos compreender a natureza porque fazemos parte dela. Assim como compreendemos pessoas em virtude de uma racionalidade de seus pensamentos e ações, assim podemos compreender as leis da natureza em razão de alguma espécie de racionalidade ou de necessidade compreensível inerente a elas.
Pelo visto, o par de termos explicação/compreensão mostrou-se fecundo na démarche por um método integrativo, uma vez que permite o aumento crescente e indefinido de inter-relações. Essa atitude de convergência estimula a ultrapassagem das barreiras disciplinares e a proliferação de teorias. Estimula também a refutação, pois, sob esse enfoque, o pensador procura eliminar suas teorias falsas para que elas morram em seu lugar. ${ }^{20}$

Nessa démarche, duas teorias, incomensuráveis em seu reduto original, poderão ser aproximadas mediante uma nova teorização onde serão aproveitados os elementos significativos retirados de ambas. Esse procedimento não será confundido com elitismo confuso, que realiza aproximações forçadas entre elementos incompatíveis.

Embora se trate de uma reflexão inicial, quer se evitar uma adesão apressada ao modismo da interdisciplinaridade e ao simplismo edificante de uma ciência unificada. ${ }^{21}$ Procura-se o aproveitamento do êxito de vivências práticas, concomitantes a uma tentativa teórica, lógica e crítica de religar métodos e conhecimentos, colocando em perspectiva uma nova prática. E não se deve esquecer que a inventividade e a abertura de novos espaços é o principal indicador de um ambiente de pesquisa científica.

Os cursos tradicionais, estruturados na multidisciplinaridade ditada pelo protocolo acadêmico, não dão conta das complexas necessidades desses novos tempos, que exigem novas formas de abordagem, denominadas interdisciplinares ou transdisciplinares. Diz-se, então, que, ao invés da convergência de epistemologias, precisa-se, isto sim, de uma epistemologia da convergência.

Essa epistemologia da convergência, nos termos dessa argumentação, é uma "necessidade objetiva que é assumida subjetivamente" 22 pelo pesquisador quando ele, como inventor, encara a "totalidade da existência como unidade" exigente da plenitude de sentido. ${ }^{23}$

Ao concluir esse texto, novas indagações inauguram um novo ciclo de inter-relações de um objeto em constru-

17 GUSDORF, op. cit., p. 20.

18 Tradução livre do original "So leuft die Bewegung des Verstehens, stehts vom Ganzem zum Teil und zurueck zum Ganzem". Cf. GADAMER, op. cit., p. 119-120. 19 POPPER, K. R. Conhecimento objetivo: uma abordagem evolucionária. São Paulo: Edusp, 1975. p. 174-175.

20 POPPER, op. cit., p. 174.

21 RAYNAUT, C. Interdisciplinaridade. Curitiba, 1992. Entrevista concedida para Ademar Heemann em 17 jun. 1992; Na "década de 1960, a idéia de interdisciplinaridade começa a tomar forma entre os diferentes projetos epistemológicos do Ocidente".

22 SAVIANI, op. cit., p. 23, em outro contexto; Japiassu lembra que "não podemos alimentar ilusões: ainda está por ser construída uma teoria da interdisciplinaridade". Cf. JAPIASSU, apud SIEBENEICHLER, p. 155.

23 BOLLNOW, O. F. Pedagogia e filosofia da existência: um ensaio sobre as formas instáveis da educação. Petrópolis: Vozes, 1974. 
HEEMANN, A. A integração de conhecimentos e a dicotomia...

ção. Mesmo que provisoriamente, acredita-se no valor heurístico desse tipo de démarche para a teoria e a metodologia da pesquisa. Reconhecendo-se as dificuldades do intento, deixa-se aberto, no entanto, o espaço para a crítica, condição primeira para o aperfeiçoamento dessa tentativa. Como disse Popper certa vez, "evitar erros é um ideal pobre: se não ousarmos atacar problemas tão difíceis que o erro seja quase inevitável, então não haverá crescimento do conhecimento". ${ }^{24}$

\section{REFERÊECIAS}

ADES, C. Psicologia diferencial. Dante Moreira Leite. Folha de São Paulo, 20 abr. 1986. Ilustrada, p. 86.

ALTHUSSER, L. Filosofia e filosofia espontânea dos cientistas. Lisboa: Presença, 1976.

BASSALO, J. M. F. O papel da intuição nas descobertas e invenções em física. Ciência e Cultura, São Paulo, v. 38, n. 11, p. 1835-1848, nov. 1986.

BOLLNOW, O. F. Pedagogia e filosofia da existência: um ensaio sobre formas instáveis da educação. Petrópolis: Vozes, 1974.

BONNER, T. J. A evolução da cultura nos animais. Rio de Janeiro: Zahar, 1983.

CAPRA, F. O ponto de mutação. São Paulo: Cultrix, 1982.

CARVALHO, R. de. Complementaridade filosófica. Cadernos de Teoria e Conhecimento, n. 7, p. 89-90, nov. 1975.

CORETH, E. Questões fundamentais de hermenêutica. São Paulo: E.P.U., 1973.

CUPANI, A. A crítica do positivismo e o futuro da filosofia. Florianópolis: Editora da UFSC, 1985.

FROTA-PESSOA, O. Sociobiologia - o fator genético. Folha de São Paulo, 2 mar. 1986.

GADAMER, H.-G. Wahrheit und Methode. Tuebingen: J.C.B. Mohr, 1965.

GUSDORF, G. A interdisciplinaridade. Ciências Humanas, Rio de Janeiro, v. 1, n. 2, p. 13-22, 1977.

HEEMANN, A. Natureza e ética: dilemas e perspectivas educacionais. 2. ed. Curitiba: Ed. UFPR, 1998.
HEIDEGGER, M. Sein und Zeit. Tuebingen: Max Niemeyer Verlag, 1977.

JAPIASSU, H. F. Introdução ao pensamento epistemológico. Rio de Janeiro: F. Alves, 1977.

KUHN, T. S. A estrutura das revoluções científicas. São Paulo: Perspectiva, 1982.

LADRIERE, J. Filosofia e práxis científica. Rio de Janeiro: Francisco Alves, 1978.

MORIN, E. O enigma do homem. São Paulo: Círculo do Livro, 1973.

PALMER, R. E. Hermenêutica. Lisboa: Edições 70, 1969.

POPPER, K. R. Conhecimento objetivo: uma abordagem evolucionária. São Paulo: Ed. da Universidade de São Paulo, 1975.

Conjecturas e refutações. Brasília: Editora da Universidade de Brasília, 1972.

RAYNAUT, C. Interdisciplinaridade. Entrevista concedida para Ademar Heemann. Curitiba, 17 jun. 1992.

SAVIANI, D. A filosofia na formação do educador. In: Educação: do senso comum à consciência filosófica. São Paulo: Cortez, 1996.

SIMPSON, G. G. A biologia e homem. São Paulo: Cultrix, 1974.

WILSON, E. O. A natureza humana. São Paulo: T. A. Queiroz, 1981 .

24 POPPER, op. cit., p. 177, declara, ainda, sobre o valor dos problemas em um contexto interdisciplinar: "os que lutaram com um problema podem ser recompensados ganhando uma compreensão de campos bastante afastados dos que se lhes são próprios." 